\title{
The New Strategic Imperative: Understanding the Female Business Traveler
}

Francine Newth, Providence College, USA

\begin{abstract}
This paper explores the characteristics, needs, and behaviors of women who travel on business and analyzes the data for potential segmentation. The study focuses exclusively on the female business traveler. The sample consists of 235 female business travelers from a variety of industries. The statistical methods include correlation analyses, factor analysis, and cluster analysis. The findings show that 6 factors explain $60.4 \%$ of the variance in characteristics, behaviors and needs of female business travelers. Cluster analysis further identifies 3 clusters: the Connective, the Empowered, and the Productive. The results show that there are three distinct types of women who travel on business. Strategies are suggested for organizations to use the findings to respond to female business travelers.
\end{abstract}

Keywords: female business traveler, business travel behaviors, needs, characteristics, hospitality strategies, resource reconfiguration

\section{INTRODUCTION}

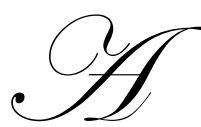

ggregate data from national travel studies show female business travelers as a viable and desirable market. In 2005, women business travelers represented $40 \%$ of all business travel worldwide (Lagace, 2005). According to a survey by NYU Tisch Center (2003), women business travelers don't feel valued by the travel industry. The survey also revealed that women view business travel as a sign of professional achievement and an important part of their job. These studies indicate that there is a need to better understand the female business traveler.

Academic studies have examined the preferences of both male and female business travelers with limited analysis of the female segment (McCleary, Weaver and Lan 1994; Weaver and Oh 1993; Radder and Wang 2006). Several studies have determined that there are differences between male and female business travelers (McCleary, Weaver and Lan 1994; Smith and Carmichael 2006; Withiam 1998) and that future research should focus on a deeper analysis of women and business travel (Smith and Carmichael 2006). This article responds to the lack of academic research on the needs and behaviors of women business travelers. For example, a study by McCleary, Weaver and Lan (1994) shows that businesswomen stay longer on international trips than businessmen and suggest more research to determine if strategies can be developed to attract international female business travelers.

The purpose of this study is to explore the needs, characteristics and behaviors of women who travel on business and to analyze the data for potential segmentation. The study focuses exclusively on the female business traveler. There is a compelling need to develop a clear profile of their demographic and psychographic attributes to better inform corporate strategies of travel-related organizations. There is also a need to inform employers as the international business traveler is viewed as a strategic resource that is often unrecognized (Welch, Welch and Worm 2007). Lastly, this study provides an opportunity for female business travelers to express and share perspectives on this essential component of their work.

\section{FEMALE BUSINESS TRAVEL RESEARCH}

Smith and Carmichael (2006) conducted a study examining women and business travel in Canada and found three types of women business travelers. The first type called 'mixing business and pleasure' represented 34\% 
of the sample. The second type 'directed business traveler' represented $19 \%$ of the sample. The third type called 'frequent business traveler' accounted for $44 \%$ of the sample. Each cluster demonstrated some key characteristics and behaviors such as highly educated, most likely to go shopping, visit friends, etc...Their findings also showed that female business travelers are different than their male counterpart, younger, unmarried, do more non-business activities when traveling and are more likely to extend their trip. Smith and Carmichael(2006) stress "the need to study women business travel behaviours beyond what is currently found in the gray literature" (p. 75).

Alamdari and Burrell (2000) conducted a supply side survey for airlines, and a demand side survey for female business travelers. On the supply side they found that airlines are focusing on the growth in female business travelers. Delta Airlines developed an executive women's travel page on their website. United Airlines trains flight attendants to treat female business travelers with the same respect as male business travelers. On the demand side they reported that nearly $40 \%$ of the respondents believe that they have different travel needs than male business travelers yet they do not want to be treated differently only in the same manner as male business travelers. Withiam (1998) also reported on a study conducted by The Travel Group which states that women business travelers are not given the same level of consideration than men business travelers.

Bowen (1998) reviewed the hospitality research with a focus on market segmentation, market targeting, and market positioning. His findings were that segmentation studies "need to go to the next level...be more specific and more directive" (p. 294). Much of the literature in hospitality and business travel focuses on business travelers in general. Researchers need to go into each market segment and look for differences (Bowen, 1998).

To summarize, it is evident that patterns of business travel characteristics for women are emerging, organizations are responding, and female business travelers differ from their male counterparts. It is also evident that the needs and behaviors of women who travel on business must be explored in greater depth.

\section{RESEARCH QUESTION}

This exploratory study seeks to determine needs, characteristics and behaviors of female business travelers, and to identify differing segments or clusters of women business travelers. The research question is three-fold: (a) What are the demographic characteristics and psychographic characteristics, behaviors and needs of female business travelers? (b) Are there significant relationships among the demographic and psychographic variables? (c) Are there "types" of female business travelers based on these variables?

\section{METHODOLOGY}

\section{Survey}

Given the lack of research in the phenomenon of interest, an exploratory survey was developed from key findings in Smith et al (2006) and the psychographic scales in Plog (2002). A pilot test of the survey was conducted with 10 women who travel on business. Modifications were made and questions were added on rank and travel business experience. The questionnaire was designed to measure three key aspects of women business travelers: business travel characteristics, demographic characteristics, and psychographic characteristics, behaviors and needs. Given the breadth of data, this analysis focuses only on demographic and psychographic characteristics, behaviors, and needs with the exception of one business travel characteristic: the business travel experience of the respondents measured in years of experience traveling on business. The travel characteristics will be the subject of a separate article.

To collect data on needs, behaviors and characteristics of women business travelers, a web-based survey was used. The survey was designed using www.qualtrics.com software and participants were offered a web link to the survey. It consisted of 28 questions grouped in three categories. The first group of questions was focused on business travel characteristics. For example, women were asked about their years of business travel experience, the scope of their business travel (regional, national, international), the areas of the world they travel to for business, the purpose of their trip, the frequency of their business trips per year, the length of their business trips, the number of nights per month away from home, the types of hotel they stay at during business travel, and whether or not their 
company had a corporate rate. These questions were used to identify general characteristics of business travel for women. The second set of questions addressed the demographic characteristics. They were asked about age group, salary range, educational level, staff or management rank, marital status, employment status (corporate employee, self-employed or other), industry and professional association. These questions were designed to provide a demographic profile of the female business traveler. The third group of questions was designed to provide researchers with insight to females' business travel behaviors in terms of their interests, attitudes, opinions, as well as their needs and preferences while traveling on business.

This article focuses on the demographic and psychographic variables to better understand female business travelers. The reason for this is that consumer needs and wants, the psychographic variables, vary closely with demographic variables (Bowen, 1998). Demographic and psychographic variables are commonly used to segment markets into distinct groups of buyers requiring different marketing approaches or different product attributes.

\section{Sample}

Phone calls were made to members of management of five women organizations to explain the study and to ask if they would like to receive a letter of invitation to participate in the study. All indicated that they would consider participating. Letters of invitation were then sent to the president of each organization. Three agreed to participate, one declined and one did not respond after a second follow-up letter. Three professional women organizations, WITI - Women in Technology International, NAWL - The National Association of Women Lawyers, and WAVE - the Women Association of Venture Equity agreed to participate and invited their members via their own websites and via their electronic newsletters which were sent to their members' email addresses. AMCF - the Association of Management Consulting firms was also contacted and agreed to invite their female consultants to participate. A total of 235 professional women who travel on business responded to the survey.

Three sampling issues in internet surveys are addressed. On the issue of representativeness, the selection of women-only organizations where traveling for business is the norm, is representative of the general population of female business travelers. Only those who travel on business answered the survey. On the issue of sampling frame, the number of invited participants is confined to the associations' memberships and their members' email addresses. Respondents could also forward the link to colleagues who travel on business. On the issue of sampling control, qualtrics only allows one response per email address and because the surveys were sent to their members identified a priori, the result is greater sampling control. Therefore the validity and reliability of the inferences about this target population is not compromised. Simsek et al (2005) find that when appropriate population is selected "data from Internet-based surveys are less vulnerable to respondent-based errors... and tend to be more reliable" (p. 184).

\section{Statistical Methods}

SPSS 16.0 was used to analyze the data. First, correlation analyses were performed to determine if any statistically significant bivariate relationships existed. Second, a factor analysis technique was used to investigate the number of underlying factors of the psychographic variables. Factor analysis is often used in data reduction to identify a number of factors that explain most of the variance that is observed. In other words, are there underlying attitudes leading people to respond to the questions as they did? Third, a cluster analysis was used to identify relatively homogeneous groups of individuals based on the resulting factors. Fourth, a cross-tab procedure between the clusters and the demographic variables was also used to provide a clear picture of who was included in each cluster.

\section{ANALYSIS OF THE DATA}

The sample consists of 235 female business travelers who travel as part of their responsibilities and represent a variety of industries (i.e. financial services, information technology and communications, legal services, etc..). $95 \%$ of the respondents are from the US and 5\% are from the following countries: Australia, Canada, China, France, Germany, India, Japan, Nigeria, and Switzerland. 


\section{DEMOGRAPHIC CHARACTERISTICS}

\section{Descriptive Statistics and Correlation Analysis}

Five demographic variables are analyzed with descriptive statistics and bivariate relationships of the sample (see Table 1). The descriptive statistics reveal that income has the highest mean score (4.57) followed by age (2.92) and rank (2.77). These variables constitute the three key demographic characteristics of female business travelers. The most important demographic variable is income. This finding is in line with income being the most often used criterion to target travel markets (Plog, 2002). In addition, this data in this study suggests that the base line income for female business travelers is $\$ 100 \mathrm{~K}$.

The bivariate relationships show that income, age, rank, marital status and education are all significantly correlated. Although the bivariate relationships are modest, they help us explain the demographic profile of our sample . For example, the data behind the relationship between rank and income suggest that, in this study, female business travelers with an income of $100 \mathrm{~K}$ hold a middle management rank. Overall, the findings show that it is important to include several demographic characteristics in target market modeling of the female business traveler segment.

Table 1 - Descriptive Statistics and Correlation Matrix of Demographic Variables

\begin{tabular}{|l|c|c|c|c|c|c|c|c|}
\hline & $\mathbf{N}$ & Mean & Std. Deviation & 1 & 2 & 3 & 4 & 5 \\
\hline 1. Income & 181 & 4.57 & 1.403 & 1 & & & & \\
\hline 2. Age & 226 & 2.92 & .951 & $.152^{*}$ & 1 & & & \\
\hline 3. Rank & 225 & 2.77 & 1.514 & $.319^{* *}$ & $.173^{* *}$ & 1 & & \\
\hline 4. Marital Status & 235 & .9277 & .27557 & -.038 & -.019 & .031 & 1 & \\
\hline 5. Education & 235 & .9787 & .25229 & -.064 & .030 & $.143^{*}$ & $.531^{* *}$ & 1 \\
\hline
\end{tabular}

**Correlation is significant at the 0.01 level (2-tailed)

*Correlation is significant at the 0.05 level (2-tailed)

Note: For the purpose of this analysis, only one travel characteristic is used, the "business travel experience" of the respondents. There are important correlations between business travel experience and income (.394**), age $\left(.499^{* *}\right)$, rank (.178**). In short, female business travelers with more business travel experience earn more income, hold a higher rank and are older. Figures 1, 2, 3 below provide graphs of three key demographic characteristics of survey respondents: income, rank, age. Figure 4 provides their number of years of business travel experience.

Figure 1 - Income Categories of Respondents with Percentage of Respondents per Income Category

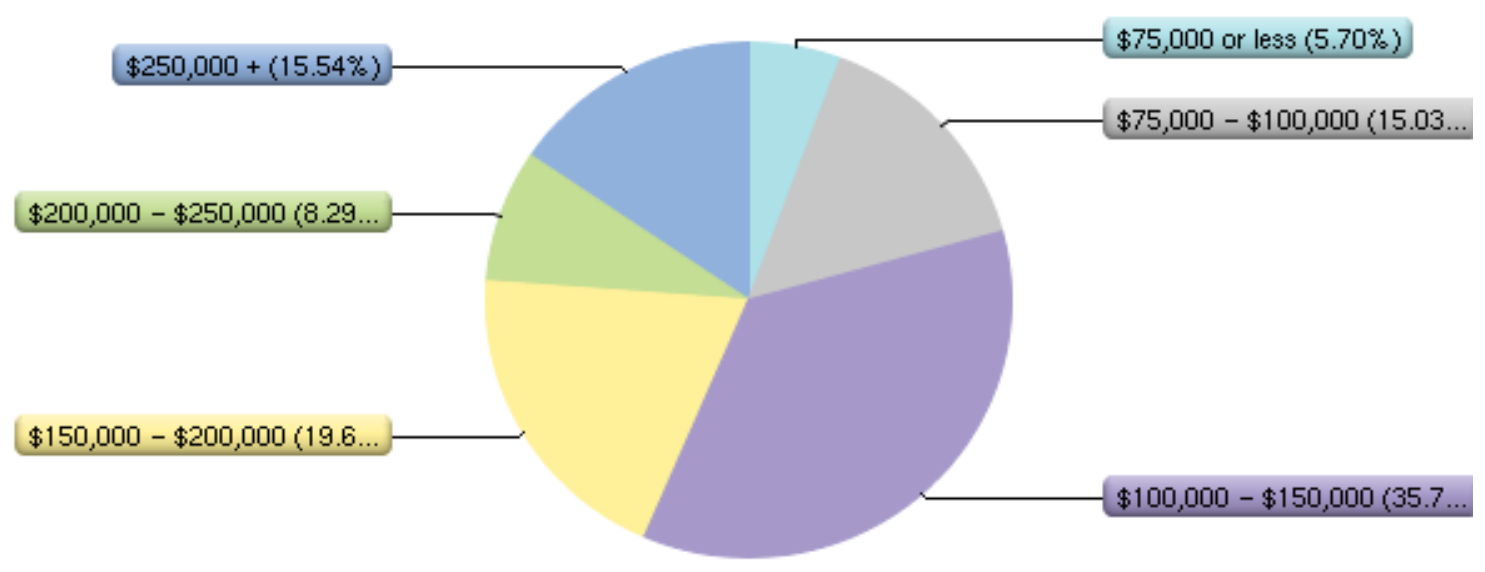


Figure 2 - Ranks of Respondents with Percentage of Respondents per Rank

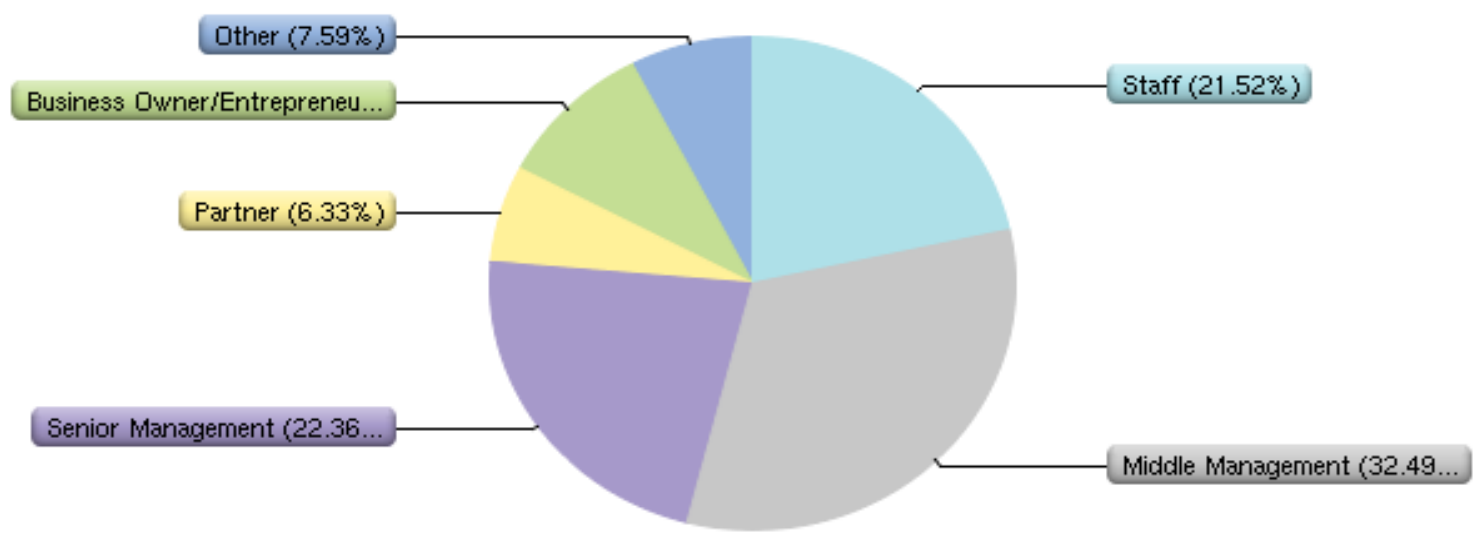

Figure 3 - Age Category of Respondents with Percentage of Respondents per Age Category

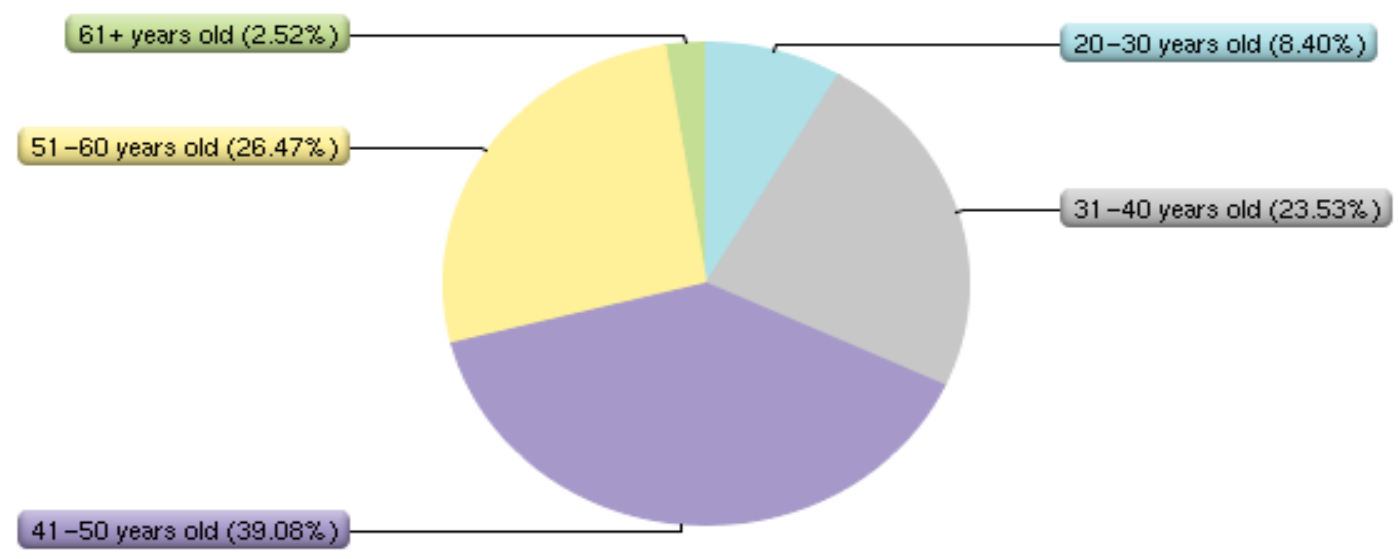

Figure 4 - Business Travel Experience of Respondents in Number of Years Categories with Percentage of Respondents per Number of Years Categories

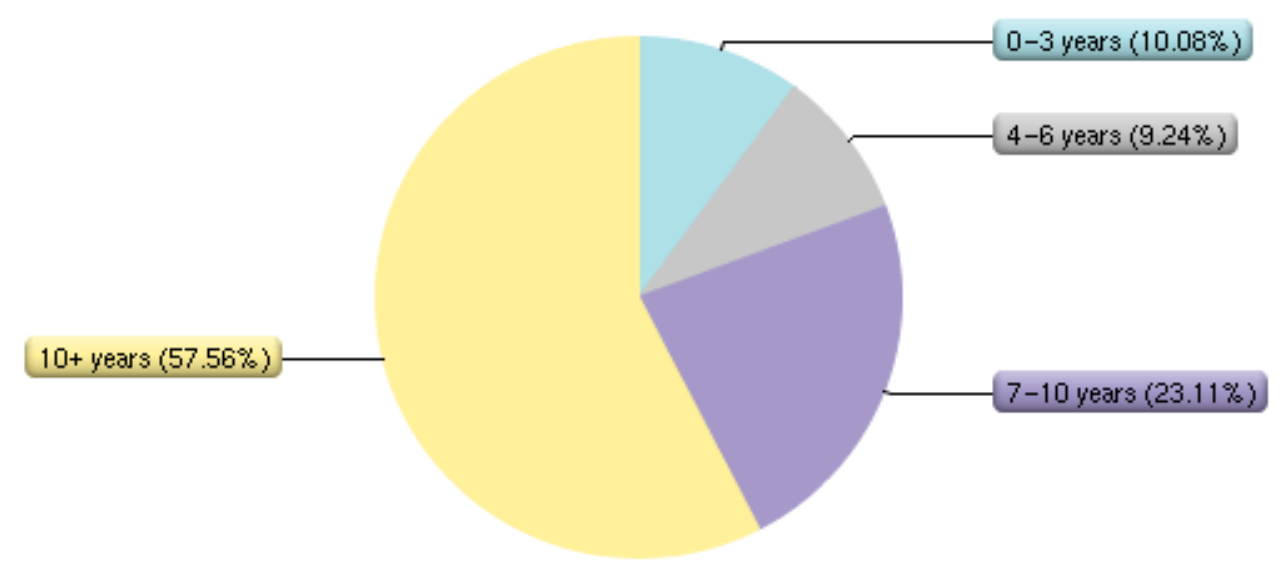




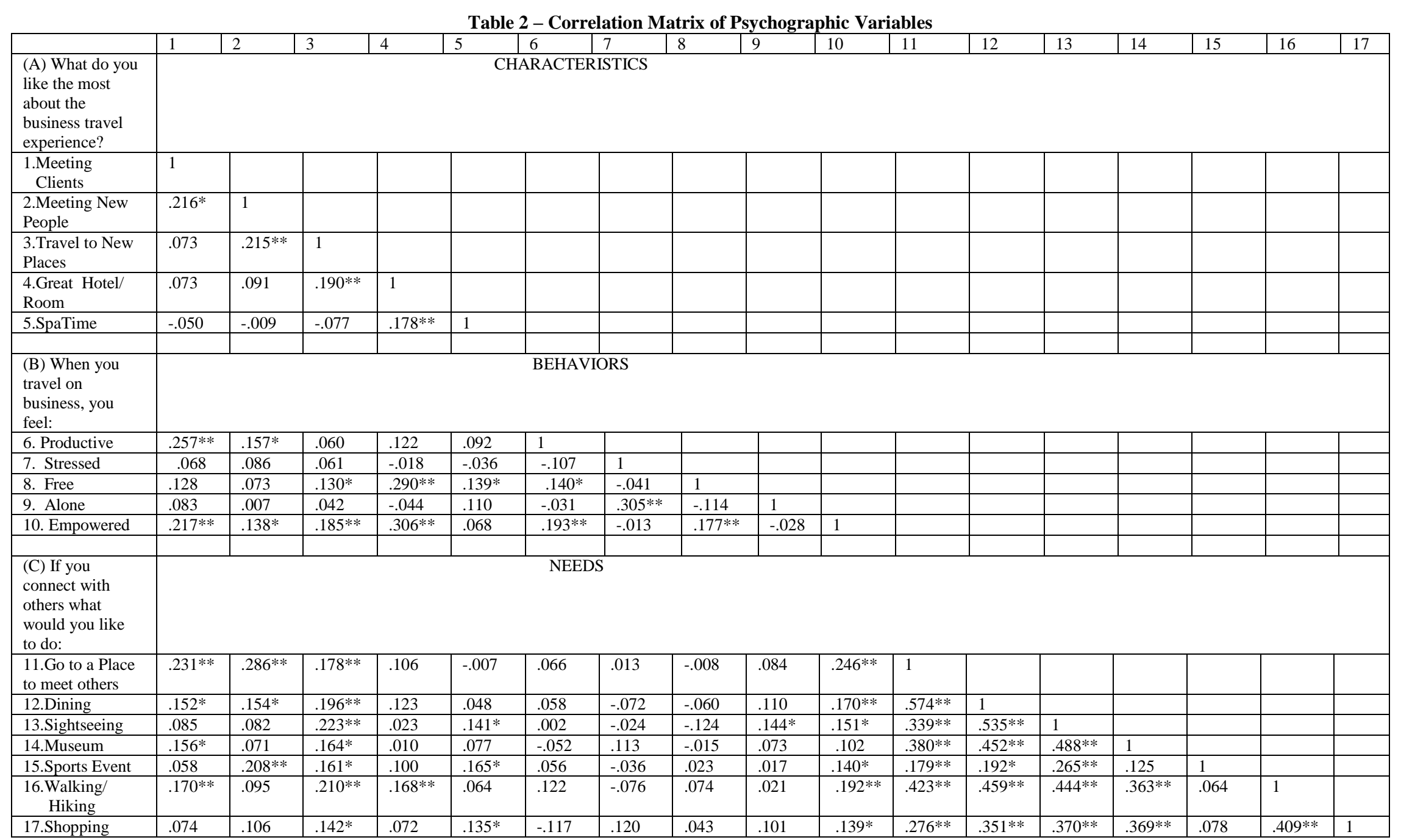

$* *$ Correlation is significant at the 0.01 level (2-tailed) $*$ Correlation is significant at the 0.05 level (2-tailed) 


\section{PSYCHOGRAPHIC CHARACTERISTICS, BEHAVIORS AND NEEDS}

\section{Correlation Analysis}

Table 2 is central to the focus of this article. It presents a correlation matrix of the 17 psychographic variables. These variables are grouped in three categories: (a) what they liked the most about their business travel experience (1-5), (b) how they feel when they travel on business (6-10), and (c) what they would like to do if they could connect with other female business travelers (11-17). The matrix reveals that "meeting clients", "feeling productive", and "feeling empowered" are significantly and positively correlated. As they travel on business to meet clients, they feel productive and empowered. This is consistent with a study (Harris and Ateljevic 2003) which examined challenges of female business travelers and found that women consider an international business trip a source of empowerment. Additionally, this study shows that if the traveler feels empowered when traveling on business, she does not feel alone or stressed. However the data provides evidence of a correlation between feeling stressed and feeling alone when traveling on business. There are also many significant correlations among the various types of social activities that female business travelers can engage in after business hours. This is consistent with a study done by Gibson and Yiannakis (2002) which found that in terms of tourist travel preferences, women are more attracted to socialized environments.

To summarize, if we look at each category separately, we find that in category (a) the important aspects of business travel is to meet clients and to meet new people; in category (b) women feel productive and empowered when they travel on business; in category (c), there are many activities that women would like to engage in, after business hours, particularly meeting and dining with other female business travelers.

\section{Factor Analysis}

The psychographic variables were factor analyzed using a principal components analysis extraction method with a varimax rotation. The results did not show any cross-loadings and the final solution consisted of six factors with eigenvalues greater than 1.0 explaining $60.4 \%$ of the variance (Table 3 ).

Based on an examination of the coefficients, the factors are titled as follows: Factor 1 The Connective, Factor 2 The Empowered, Factor 3 The Productive, Factor 4 The Stressed and Alone, Factor 5 The Explorer, and Factor 6 The Relaxed. These factors reflect what women business travelers like the most about the business travel experience, how they feel when they travel on business, and what they like to do in their free time. It is interesting to note that Factor 1 The Connective "connecting with other female business travelers when traveling on business to do various activities" is the strongest factor explaining $21.1 \%$ of the variance with an eigenvalue of 3.59 . These business travelers have a strong desire to meet other female business travelers who are also traveling on business to go "dining", "sightseeing", visit a "museum or art gallery", go "walking or hiking", and go "shopping" in their free time after business hours. Factor 2 The Empowered explains $10.8 \%$ of the variance and consists of female business travelers who feel free and empowered when traveling on business. It is also important to them to stay at a great hotel/room. Factor 3 The Productive explains $8 \%$ of the variance and these travelers feel very productive when traveling on business because they can focus on meeting with their clients or customers. Factor 4 The Stressed explains $7.9 \%$ of the variance and includes female business travelers who feel very stressed and alone when they are away on business. Factor 5 The Explorer also views her business travel as an opportunity to meet new people, travel to new places, and likes to attend sports events during her free time when traveling on business. This factor explains $6.5 \%$ of the variance. Factor 6 The Relaxed is the traveler who goes to the spa when she has free time. This factor explains $6.3 \%$ of the variance.

These factors provide evidence that there are common underlying characteristics which explain the differences in responses. For example, the empowered factor tells us that those who feel strongly that business travel gives them a sense of empowerment can help us understand the female business traveler's related motivations and needs. The question then becomes how can we measure empowerment and use it to help define services or markets? The best way to do that is to find out the nuances of why they feel empowered. For example is their ability to make decisions more critical to their tasks when away on business? If so, they may tend to reward themselves (e.g. using 
more hotel services). Further exploring the challenges, solutions, and rewards of women and business travel can be a source of creativity for the providers of services.

The next stage of this research includes the development of constructs for each cluster to further refine the findings and gain greater insight. Future research is discussed briefly in the last section "Limitations and Suggestions".

Table 3

Factor Analysis Results of Psychographic Variables

\begin{tabular}{|c|c|c|c|c|c|c|}
\hline & $\begin{array}{c}\text { Factor } \\
1 \\
\text { Connective }\end{array}$ & $\begin{array}{c}\text { Factor } \\
2 \\
\text { Empowered }\end{array}$ & $\begin{array}{c}\text { Factor } \\
3 \\
\text { Productive }\end{array}$ & $\begin{array}{c}\text { Factor } \\
4 \\
\text { Stresse }\end{array}$ & $\begin{array}{c}\text { Factor } \\
5 \\
\text { Explorer }\end{array}$ & $\begin{array}{c}\text { Factor } \\
6 \\
\text { Relaxed }\end{array}$ \\
\hline \multicolumn{3}{|c|}{ (A) What do you like the most about the business travel experience? } & \multicolumn{3}{|c|}{ CHARACTERISTICS } & \\
\hline Meeting with clients/customers & .170 & .103 & .720 & . 191 & .007 & -.155 \\
\hline Meeting new people & .066 & .101 & .301 & .129 & .614 & -.223 \\
\hline Traveling to new places & .226 & .382 & -.141 & .085 & .468 & -.344 \\
\hline Staying at a great hotel/room & .063 & .726 & .018 & -.038 & .106 & .138 \\
\hline Having time for the spa & .077 & .212 & -.011 & .071 & .033 & .846 \\
\hline \multicolumn{3}{|c|}{ (B) When you travel on business you feel: } & \multicolumn{2}{|c|}{ BEHAVIORS } & & \\
\hline Empowered & .202 & .496 & .290 & -.030 & .160 & -.006 \\
\hline Alone & .115 & -.173 & .105 & .714 & .023 & .253 \\
\hline Stressed & .033 & .046 & -.068 & .834 & .027 & -.142 \\
\hline Productive & -.061 & .130 & .738 & -.167 & .080 & .169 \\
\hline Free & -.092 & .732 & .096 & -.041 & -.079 & .044 \\
\hline \multicolumn{3}{|c|}{ (C) Activities with other female business travelers: } & \multicolumn{2}{|c|}{ NEEDS } & & \\
\hline Going to a place to meet & .642 & .021 & .271 & .007 & .236 & -.154 \\
\hline Dining & .775 & -.040 & .128 & -.079 & .174 & .015 \\
\hline Sightseeing & .740 & -.105 & -.050 & -.004 & .222 & .194 \\
\hline Museum/Art Gallery & .712 & -.014 & -.030 & .136 & .016 & .000 \\
\hline Sports Event & .123 & .009 & -.033 & -.080 & .771 & .324 \\
\hline Walking/Hiking & .725 & .029 & -.141 & -.115 & -.094 & -.027 \\
\hline Shopping & .637 & .202 & -.184 & .218 & -.077 & .043 \\
\hline Eigenvalues & 3.597 & 1.839 & 1.360 & 1.275 & 1.118 & 1.083 \\
\hline$\%$ of variance explained & 21.159 & 10.818 & 8.000 & 7.499 & 6.575 & 6.373 \\
\hline Cumulative variance explained & 21.159 & 31.977 & 39.978 & $\mathbf{4 7 . 4 7 7}$ & 54.052 & 60.425 \\
\hline
\end{tabular}

\section{Cluster Analysis}

Cluster analysis was used to examine if the six factor types would cluster on the basis of similar characteristics, behaviors, and needs about traveling on business. Ward's hierarchical cluster analysis was first used and the agglomeration schedule and dendogram identified three clusters for the six factors with the following cluster membership: factors 1, 4, 5 for cluster 1, factor 2 for cluster 2, and factors 3 and 6 for cluster 3 . Cluster 1 unites three factors that are related by the need to connect to other people. The Connective wants to be involved in different activities with other female business travelers, the Stressed although very much alone, does enjoy meeting clients and other people as does the Explorer. Cluster 2 reflects only one factor and suggests that the Empowered's unique dominant characteristics, a feeling of freedom when traveling on business, adds to her empowerment and productivity. Cluster 3 includes the Productive and the Relaxed with each showing the highest rotated scores on "feeling productive". One interpretation is that they are both very productive but one needs to focus more on her clients and the other has a greater need to relax. Cluster 1 has 74 cases, cluster 2 has 73 cases and cluster 3 has 88 
cases totaling 235 cases. To further assess the clusters, using a Scheffe post hoc test multiple comparisons, it was determined that statistically significant differences (.000) existed among the three clusters. Based on psychographic factors, three clusters of female business travelers have emerged: the Connective, the Empowered, and the Productive.

\section{PSYCHOGRAPHIC CHARACTERISTICS OF CLUSTERS}

The psychographic characteristics were determined from the question: what do you like the most about the business travel experience? The most important characteristic of the Productive is to meet clients or customers, for the Empowered it is to stay in a great hotel room, and for the Connective it is to meet new people. Across the three clusters, the Connective, the Empowered and the Productive, like the business travel experience because they meet with their clients or customers and they have an opportunity to meet other people in the organization. In addition, two of three clusters, the Connective and the Empowered, indicate that their business travel experience is also a way to travel to new places.

Figure 5 provides an overview of the percentage of survey respondents selecting one or more characteristics of what they like about their business travel experience.

Figure 5 - Characteristics: (what they like about the business travel experience)

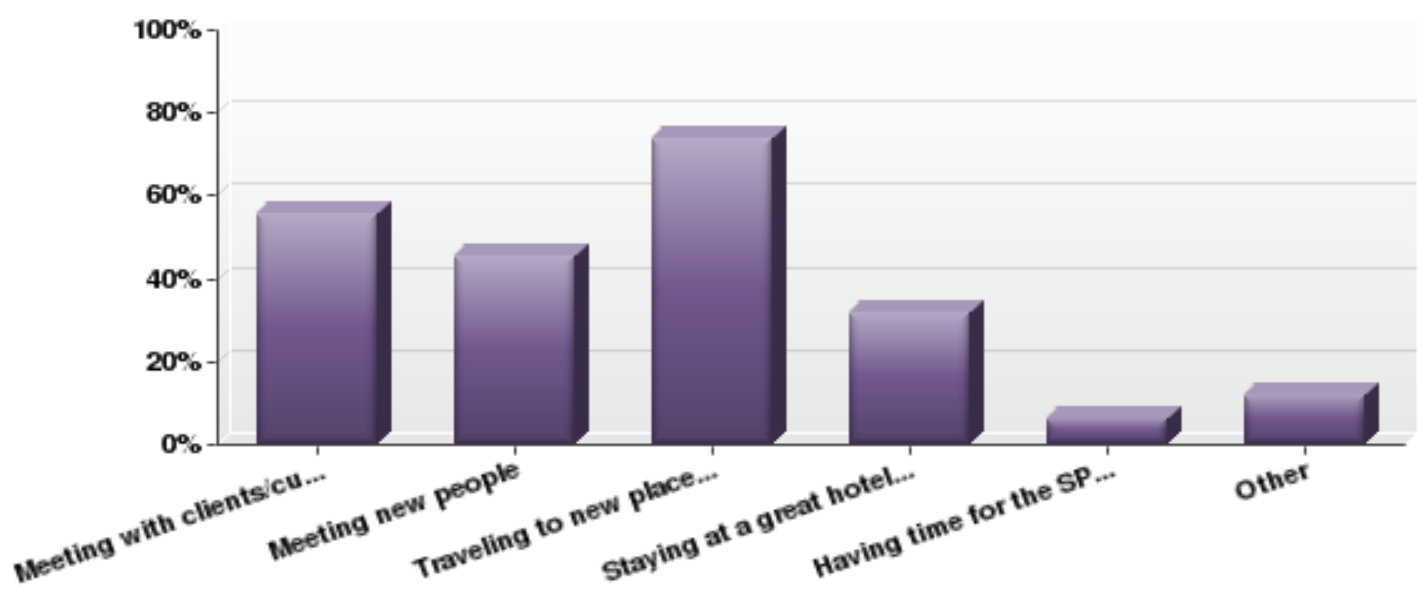

\section{PSYCHOGRAPHIC BEHAVIORS OF CLUSTERS}

The psychographic behaviors were determined from the question: when you travel on business you feel. The feeling of empowerment is common to all three clusters. The feeling of freedom is common to the Empowered and the Productive. The only cluster displaying behaviors of freedom, empowerment, being productive and connective is the Empowered.

Figure 6 provides an overview of the percentage of survey respondents selecting one or more behaviors of how they feel when they travel on business.

\section{PSYCHOGRAPHIC NEEDS OF CLUSTERS}

The psychographic needs were determined from the question: if you connect with others, what would you like to do? The Productive shows no need to connect with others to engage in various activities after business hours. The two clusters with the most needs are the Connective and the Empowered. The most important social need for 
the Connective is to go dining. For the Empowered, the most important need is to go to a place to meet others. Both like to go dining, to a place to meet others, walking or hiking, sightseeing, shopping, and attend a sports event. Only the Connective likes to go to the museum.

Figure 7 provides an overview of the percentage of survey respondents selecting one or more needs showing what they would like to do if they could connect with other female business travelers after hours.

Figure 6 - Behaviors: (how they feel when they travel on business)

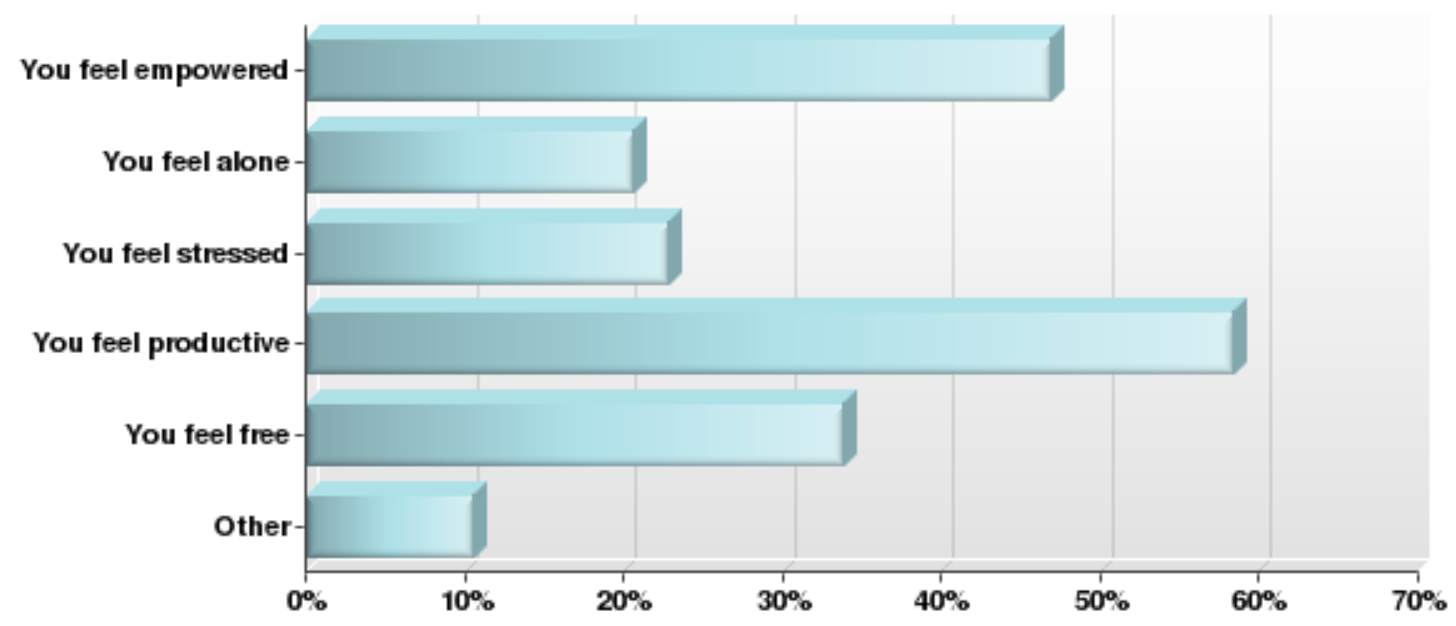

Figure 7 - Needs: (what they like to do with other female business travelers)

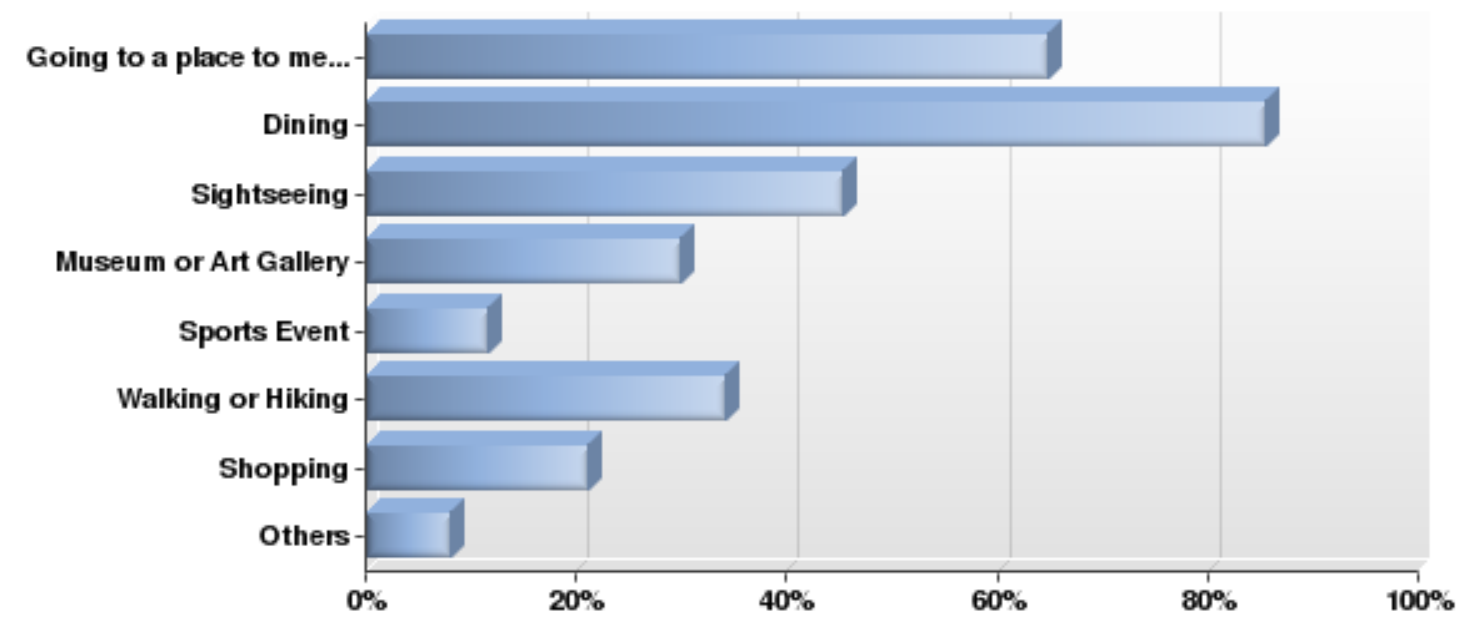

\section{DEMOGRAPHIC CHARACTERISTICS OF CLUSTERS}

Table 4 shows the demographic profiles of women business travelers in percentages (\%) for each cluster. It also includes one key travel metric, the business travel experience of each respondent. The table illustrates differences among the clusters in terms of business travel experience, income, rank, age, and education. A 
comparison across the clusters reveals the following attributes in each of the 5 categories.

1. Business Travel Experience

- Cluster 1 The Connective - has the most experienced business travelers with 10+ years and the smallest percentages in the other three levels of travel experience.

- Cluster 2 The Empowered - has the most women with 7 to 10 years of business travel experience as well as having the most women with 0 to 3 years.

- Cluster 3 The Productive - has the most women with 4 to 6 years of travel experience.

Note: the highest business travel experience concentration for each cluster is $10+$ years.

2. Income

- Cluster 1 The Connective - shows that two income brackets have the highest percentages: $\$ 100,000$ to $\$ 150,000(40 \%)$ and $\$ 200,000$ to $\$ 250,000(9.1 \%)$.

- Cluster 2 The Empowered - shows the highest percentage of women earning $\$ 250,000+(18 \%)$.

- Cluster 3 The Productive - has the greatest percentage of women earning between $\$ 150,00$ and $\$ 200,000(35.4 \%)$.

Note: the highest income concentration for each cluster is between $\$ 100,000$ and $\$ 150,000$ which suggest that income of at least $100 \mathrm{~K}$ is a key characteristic of the female business travel segment.

3. Rank

- Cluster 1 The Connective - does not have any highest concentration in rank when compared to the other clusters. It is however very close to cluster 3 on having more women in Middle Management positions (35.4\%).

- Cluster 2 The Empowered - has more women in several ranks, Staff (25\%), Senior Management (23.6\%), Partners (8.3\%) and Business Owners (13.9\%).

- Cluster 3 The Productive - has the greatest percentage of women in Middle Management (36.4\%).

Note: the highest rank concentration for each cluster is Middle Management.

4. Age

- Cluster 1 The Connective - reveals that 51 to 60 is the prevalent age bracket (36.9\%).

- $\quad$ Cluster 2 The Empowered - has the most respondents in the 31 to 40 age bracket (27.4\%).

- Cluster 3 The Productive - has the greatest percentage of 41 to 50 (45.5\%).

5. Education

- Cluster 1 The Connective - does not have any highest concentration in terms of education when compared to the other clusters. It is however very close to cluster 2 on having more women with graduate degrees $(41.9 \%)$.

- Cluster 2 The Empowered - has more women with graduate (42.5\%) and postgraduate education $(24.7 \%)$.

- Cluster 3 The Productive - has the greatest percentage of respondents with undergraduate education $(39.8 \%)$.

Summary of dominant demographic and psychographic characteristics for each cluster:

Cluster 1 - The Connective has the most experienced business travelers (10+ yrs) in their 50's earning between $\$ 100,000$ to $\$ 150,000$ and $\$ 200,000$ to $\$ 250,000$, holding middle management positions and having a graduate education. They like to meet new people, meet their clients or customers and travel to new places. They feel empowered and like to connect with other female business travelers to engage in various activities.

Cluster 2 - The Empowered consists of experienced business travelers (7 to 10 yrs) who are in their 40's earning $\$ 250,000+$, holding mostly senior management positions and having a graduate education. They like to stay at a great hotel, meet their clients or customers, meet new people and travel to new places. Their sense of empowerment is very strong combined with their sense of freedom. They are productive and also like to connect 
with other female business travelers when they travel on business.

Cluster 3 - The Productive includes women with 4 to 6 years of business travel experience with the most women in their 40 's earning between $\$ 150,000$ to $\$ 200,000$, in middle management positions and having an undergraduate education. They focus on meeting their clients or customers. They feel empowered and free when they travel on business.

It is important to recognize that the clusters reflect dominant characteristics and are not mutually exclusive. For example, if someone is more connective it does not mean that she is not productive or feels less productive. It simply shows that she has strong preferences toward meeting others when traveling on business.

\section{Table 4 - Demographic Profiles of Female Business Travelers by Cluster}

\begin{tabular}{llll}
\hline & Cluster 1 & Cluster 2 \\
Characteristics & $(n=74)$ & Empowered & Cluster 3 \\
$(n=73)$ & $\begin{array}{l}\text { Productive } \\
(n=88)\end{array}$ \\
\hline
\end{tabular}

\begin{tabular}{|c|c|c|c|c|}
\hline \multicolumn{5}{|l|}{ Experience } \\
\hline & $(n=235)$ & & & \\
\hline $0-3 y r s$ & $(10.2) \%$ & $7.7 \%$ & $12.3 \%$ & $10.2 \%$ \\
\hline $4-6$ & ( 8.8$)$ & 6.2 & 6.8 & 12.5 \\
\hline $7-10$ & (23.9) & 18.2 & 28.8 & 23.9 \\
\hline $10+$ & $(57.1)$ & 67.7 & 52.1 & 53.4 \\
\hline \multicolumn{5}{|l|}{ Income } \\
\hline$<\$ 75,000$ & $(5.0)$ & 3.6 & 4.9 & 6.2 \\
\hline $75-100$ & $(15.5)$ & 18.2 & 16.4 & 12.3 \\
\hline $100-150$ & $(36.5)$ & 40.0 & 34.4 & 35.4 \\
\hline $150-200$ & (19.9) & 16.4 & 18.0 & 24.6 \\
\hline $200-250$ & $(7.2)$ & 9.1 & 8.2 & 4.6 \\
\hline $250+$ & $(16.0)$ & 12.7 & 18.0 & 16.9 \\
\hline \multicolumn{5}{|l|}{ Rank } \\
\hline Staff & (20.4) & 20.0 & 25.0 & 17.0 \\
\hline Middle Mgt & (32.4) & 35.4 & 25.0 & 36.4 \\
\hline Senior Mgt & $(22.7)$ & 21.5 & 23.6 & 22.7 \\
\hline Partner & $(6.2)$ & 3.1 & 8.3 & 6.8 \\
\hline Bus. Owner & $(10.2)$ & 10.8 & 13.9 & 6.8 \\
\hline Other & $(8.0)$ & 9.2 & 4.2 & 10.2 \\
\hline \multicolumn{5}{|l|}{ Age } \\
\hline $20-30$ & $(7.5)$ & 3.1 & 8.2 & 10.2 \\
\hline $31-40$ & (24.3) & 23.1 & 27.4 & 22.7 \\
\hline $41-50$ & (39.8) & 33.8 & 38.4 & 45.5 \\
\hline $51-60$ & (25.7) & 36.9 & 24.7 & 18.2 \\
\hline $61+$ & $(2.7)$ & 3.1 & 1.4 & 3.4 \\
\hline \multicolumn{5}{|l|}{ Education } \\
\hline Undergrad. & $(34.9)$ & 31.1 & 32.9 & 39.8 \\
\hline Graduate & $(40.0)$ & 41.9 & 42.5 & 36.4 \\
\hline PostGrad. & (20.9) & 13.5 & 24.7 & 23.9 \\
\hline
\end{tabular}

\section{CONCLUSIONS AND IMPLICATIONS}

The purpose of this study was to explore and understand the needs, characteristics, and behaviors of the female business traveler. The results indicate that when women business travelers are examined in depth, three 
distinct clusters emerge. The relationships between demographic and psychographic variables are statistically significant and the findings are meaningful. While six factors emerged from the factor analysis, three factors most strongly differentiated between the clusters of female business travelers: the need to connect with others, the feeling of empowerment and the feeling of being productive. According to this finding, there are three distinct types of female business travelers. This finding is important for marketers interested in the segmentation of the female business traveler market. Not all women travel for business in the same fashion. Not all women feel the same way about the business travel experience. Not all women engage in the same activities while traveling for business. For example, they stay at different hotels, some feel productive while others feel stressed and alone, and some prefer to engage in activities with others while traveling on business.

This exploratory study addresses a neglected phenomenon and has strategic implications for many organizations and individuals. For the hospitality industry, efforts might be made to develop social networks to respond to female business travelers who are more "Connective". Strategies to build on the characteristics of all three types of women who travel on business will necessitate the creation of innovative partnerships across a number of organizations. For employers, the use of the psychographic findings can help reconfigure resources to respond to the needs and behaviors of female business travelers and perhaps establish new business practices. For the female business traveler, the findings can help to better understand her role as paramount to the success of her organization and her own career success.

If the trend continues, the implications are of considerable importance and the hospitality industry in particular can benefit the most.

\section{LIMITATIONS AND SUGGESTIONS}

This research was a first step in exploring the attitudes, interests, and motivations specific to women who travel on business.

There is much to be learned in this area of inquiry. Follow up interviews with respondents will help develop appropriate constructs for further investigation into the three clusters. A testing of the constructs of Connective, Empowered, and Productive could provide the much needed conceptual foundation in psychographic travel research of the female business traveler (Plog, 2002). In particular, this would prove to be very insightful and constructive for the hospitality industry to better serve and attract the female business traveler.

\section{Take-Away Points}

\section{Characteristics}

Female business travelers like the business travel experience for two reasons: they like to meet with their clients or customers, and they like to meet new people. (These two psychographic characteristics appear under all 3 clusters)

\section{Behaviors}

Female business travelers feel empowered when they travel on business. (This is the only psychographic behavior which is common to all 3 clusters)

Needs

Female business travelers have the need to connect with other female business travelers when away on business. (The need to engage in various activities with other female business travelers appears in 2 clusters: Connective and Empowered)

\section{ACKNOWLEDGEMENT}

The author gratefully acknowledges the participation of three important women organizations, WITI Women 
in Technology International, NAWL National Association of Women Lawyers, and WAVE Women Association of Venture Equity. I also wish to thank AMCF the Association of Management Consulting firms for the participation of their female consultants.

I am very thankful to all the members who took time out of their day to share their thoughts and contribute to this collective knowledge.

Note: Respondents made numerous comments which could not be included in this analysis but will be the subject of other articles.

\section{AUTHOR INFORMATION}

Dr. Francine Newth is an Assistant Professor of Management in the School of Business at Providence College. She has served as Chair of the Department of Management, MBA Director and as Acting Dean of the School of Business. Her research areas are corporate strategy, global strategic alliances, and hospitality strategy. She is a member of the graduate and undergraduate faculty.

\section{REFERENCES}

1. Alamdari, F., and J. Burrell. 2000. Marketing to female business travellers. Journal of Air Transportation World Wide 5 (2): 3-18.

2. Bowen, J.T. 1998. Market segmentation in hospitality research: No longer a sequential process. International Journal of Contemporary Hospitality Management 10 (7): 289-296.

3. Canadian Tourism Commission. 2004. Canadian tourism facts and figures 2003. Ottawa, Canada: Tourism Statistics Program.

4. Gibson, H., and A. Yiannakis. 2002. Tourist roles: Needs and the lifecourse. Annals of Tourism Research 29 (2): 358-383.

5. Harris, C., and I. Ateljevic. 2003. Perpetuating the male gaze as the norm: Challenges for 'her' participation in business travel. Tourism Recreation Research 28 (2): 21-30.

6. Lagace, M. 2005. (Editor) The Hidden Market of Female Travelers. Harvard Business School Working Knowledge.

7. McCleary, K. W., P. A. Weaver, and L. Lan. 1994. Gender-based differences in business travelers' lodging preferences. Cornell Hotel and Restaurant Administration Quarterly 35 (2): 51.

8. NYU Tisch Center Survey. 2003. Coming of age: The continuing evolution of female business travelers.

9. Plog, S. C. 2002. The Power of Psychographics and the concept of venturesomeness. Journal of Travel Research 40:244-251.

10. Radder, L., and Y. Wang. 2006. Dimensions of guest house service: Manager's perceptions and business travellers' expectations. International Journal of Contemporary Hospitality Management 18 73): 554-562.

11. Simsek, Z., J. F. Veiga, and M. H. Lubatk. 2005. Challenges and Guidelines for conducting internet-based surveys in strategic management rersearch. in Research methodology in strategy and management 2:179186. Elsevier Ltd.

12. Smith, W. W., and B. A. Carmichael. 2006. Domestic business travel in Canada with a focus on the female market. Journal of Travel and Tourism Marketing 21(1): 65-76.

13. Weaver, P. A., and H. C. Oh. 1993. Do american business travelers have different hotel service. International Journal of Contemporary Hospitality Management 5 (3): 16-21.

14. Welch, D. E., L. S. Welch, and V. Worm. 2007. The international business traveller: a neglected but strategic human resource. The International Journal of Human Resource Management 18 (2): 173-183.

15. Withiam, G. 1998. Studying women business travelers. Cornell Hotel and Restaurant Administration Quarterly 39 (4): 8. 